\title{
Jejunogastric intussusception presented with hematemesis: a case presentation and review of the literature Athanasios J Archimandritis ${ }^{1}$, Nikos Hatzopoulos ${ }^{1}$, Petros Hatzinikolaou ${ }^{1}$, Stavros Sougioultzis ${ }^{1}$, Dimitris Kourtesas ${ }^{1}$, George Papastratis ${ }^{2}$ and Michalis Tzivras ${ }^{1}$
}

\author{
Address: ${ }^{1}$ Department of Pathophysiology, Gastroenterology Section, and Department of Internal Medicine, University of Athens Medical \\ School, "Liako" General Hospital, Athens, Greece \\ ${ }^{2}$ Department of Propedeutic Surgery, University of Athens Medical School, "Laiko" General Hospital, Athens, Greece. \\ E-mail: Athanasios J Archimandritis - aarchim@ hotmail.com Nikos Hatzopoulos - nhatzop@ hotmail.com Petros Hatzinikolaou - \\ pchatzi@otenet.gr Stavros Sougioultzis - ssougiou@caregroup.harvard.edu Dimitris Kourtesas - dkourtesas@ hotmail.com George Papastratis \\ - gipapastratis@yahoo.com Michalis Tzivras - mtzivr@hotmail.com
}

Published: 04 January 2001

BMC Gastroenterology 200 I, I:I
Received: 05 December 2000

Accepted: 04 January 2001

This article is available from: http://www.biomedcentral.com/I47I-230X/I/I

\begin{abstract}
Background: Jejunogastric intussusception $(J G l)$ is a rare but potentially very serious complication of gastrectomy or gastrojejunostomy. To avoid mortality early diagnosis and prompt surgical intervention is mandatory.

Case presentation: A young man presented with epigastric pain and bilous vomiting followed by hematemesis, 10 years after vagotomy and gastrojejunostomy for a bleeding duodenal ulcer. Emergency endoscopy showed JGI and the CT scan of the abdomen was compatible with this diagnosis. At laparotomy a retrograde type II, JGI was confirmed and managed by reduction of JGI without intestinal resection. Postoperative recovery was uneventful.

Conclusions: JGI is a rare condition and less than 200 cases have been published since its first description in 1914. The clinical picture is almost diagnostic. Endoscopy performed by someone familiar with this rare entity is certainly diagnostic and CT-Scan of the abdomen could also help. There is no medical treatment for acute JGI and the correct treatment is surgical intervention as soon as possible.
\end{abstract}

\section{Introduction}

Jejunogastric intussusception (JGI) is a rare complication of gastrectomy or gastrojejunostomy[1] which can occur any time after the gastric operation[2]. Early diagnosis of this condition and prompt surgical intervention is mandatory: a mortality of $10 \%$ and even as high as of $50 \%$ has been reported if operation has been performed $48 \mathrm{~h}$ or later after the onset of severe symptoms, respectively[3,4]. Emergency endoscopy, carried out by endoscopists aware of this condition and its endoscopic picture, can put the correct diagnosis very soon. We de- scribe a young patient with JGI, who was admitted to the hospital with the diagnosis of upper gastrointestinal (GI) bleeding. JGI was subsequently diagnosed by an emergency upper GI endoscopy.

\section{Case Report}

A 31-year-old patient was admitted to the hospital because $24 \mathrm{~h}$ before he presented severe colicky epigastric pain followed by bilous vomiting and subsequently by hematemesis. There was a past history of vagotomy and gastrojejunostomy carried out 10 years before because of 


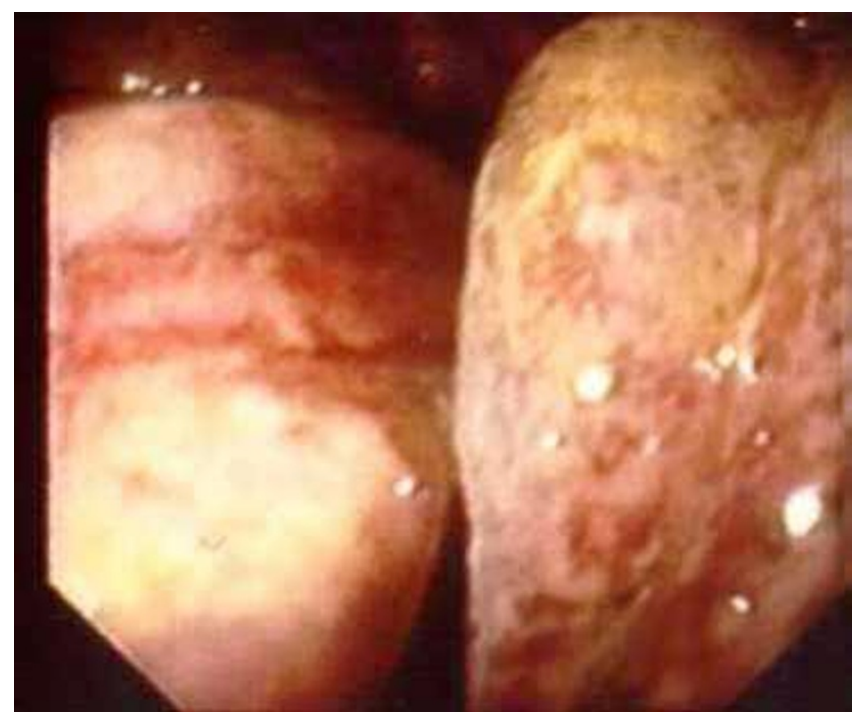

Figure I

Endoscopic picture: A bulky, lobulated congestive mass with petechial hemorrhage is seen.

a bleeding duodenal ulcer. Postoperative recovery was uneventful and, since then, the only complaint of the patient was the feeling of an early postprandial gastric fullness. On physical examination there was a mildly distented abdomen, epigastric tenderness and, on deep palpation, a vague feeling of an epigastric mass. The usual laboratory investigation was unremarkable except of an elevated WBC $\left(15610^{3} / \mathrm{L}\right)$. Emergency endoscopy disclosed a bulky, lobulated, congestive mass with petechial bleeding, protruding through the stoma into the gastric lumen, that occupied practically the anterior wall of the stomach and part of the greater curvature. The mass was sharply demarcated and the adjacent gastric mucosa was normal (fig. 1,2,3,4). An emergency CT scan of the abdomen was performed: it showed a distented stomach containing a non-homogeneous mass and a small quantity of ascitic fluid (fig. 5,6). The diagnosis of JGI was established and a laparotomy was performed. At laparotomy, the efferent loop was found intussuscepted in a retrograde way into the gastric lumen. Reduction of the JGI was performed without resection of the intussuscepted intestine, that was oedematous with serosal petechiae but absolutely viable. Postoperative recovery was uneventful and the patient was discharged home.

\section{Discussion}

Jejunogastric intussusception (JGI) was described in 1914 by Bozzi[5] in a patient with gastrojejunostomy. Eight years later this complication was also reported in a patient with Billroth II resection.[6] Subsequently, a large number of isolated cases and small series have been published and the reviews of the literature showed that less than 200 cases have been reported $[1,2,7,8,9,10]$.

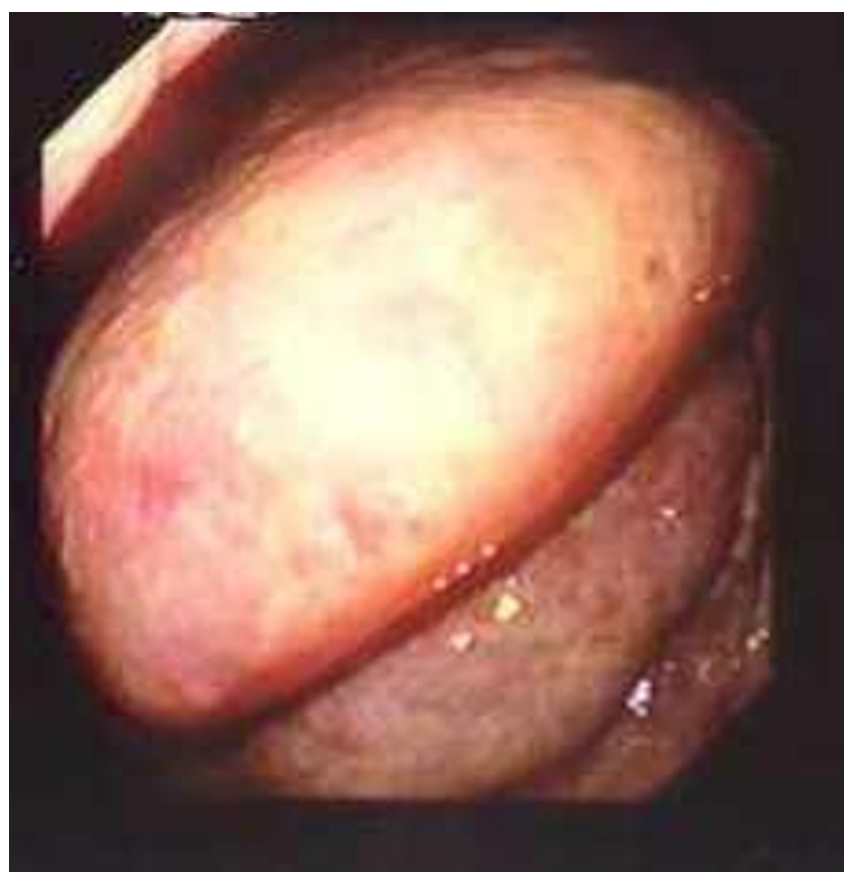

Figure 2

Endoscopic picture: A congested intestinal loop protruding through the stoma into the stomach.

Thus, JGI seems to be a rare complication after gastrojejunostomy or Billroth II gastrectomy; it also has been described rarely in association with previously placed gastrostomy tubes[11].

Occasionally, jejunojejunal or jejunoduodenal intussusception have been observed after total gastrectomy[12,13,14] and one case of duodenogastric intussusception after Billroth I gastrectomy[7]. It is interesting to point out that only 16 well-documented cases have been recognized at the Mayo Clinic in a period of 72 (1907-1980) years[1]. Three anatomic types of JGI have been described:[3] type I concerns the afferent loop, type II the efferent loop and type III represents a combined form. It has been stated that type II or retrograde efferent loop intussusception is the most common (80\%) with the two other types accounting for $10 \%$ each[15]. In the case presented, a type II JGI was documented.

There is a wide variation in the lapse time between the gastric operation and the JGI to occur: 6 days to 20 years and 8 days to 19 years in patients with gastroanastomosis and partial gastrectomy respectively[2]. Ten years was the lapse time in the present case. The cause(s) of JGI is poorly understood[1]. Various factors have been incriminated such as hyperacidity, long afferent loop, jejunal spasm with abnormal motility, increased intra-abdominal pressure, retrograde peristalsis etc. Probably, retrograde peristalsis, which can occur in normal people prior 


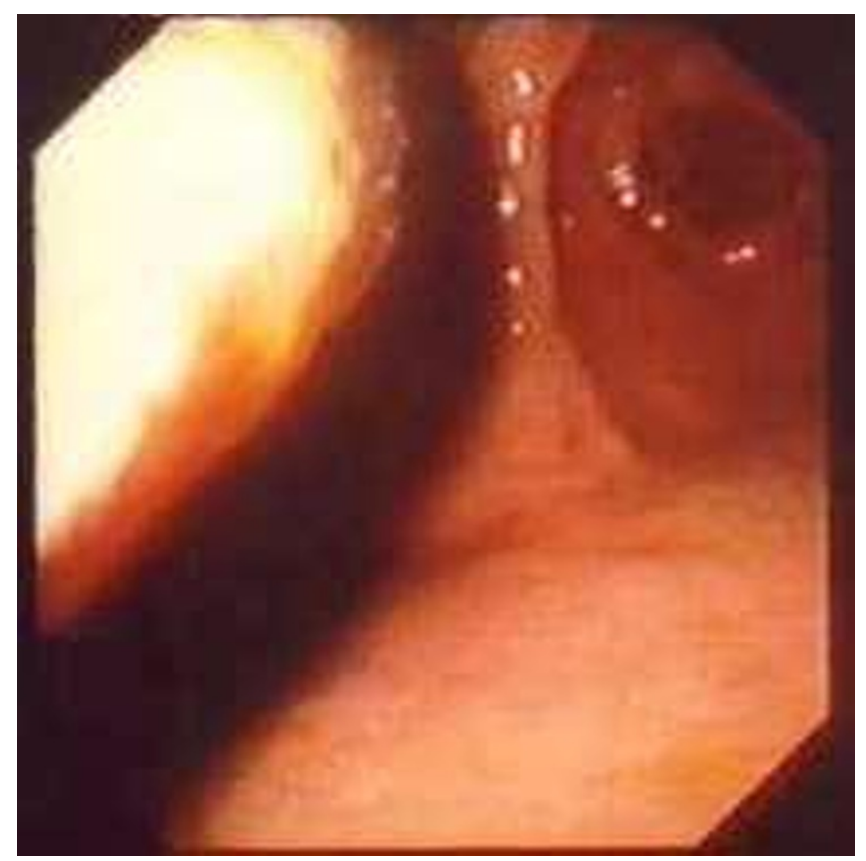

\section{Figure 3}

Endoscopic picture: Another view showing that the mass was sharply demarcated and the adjacent gastric mucosa was normal.

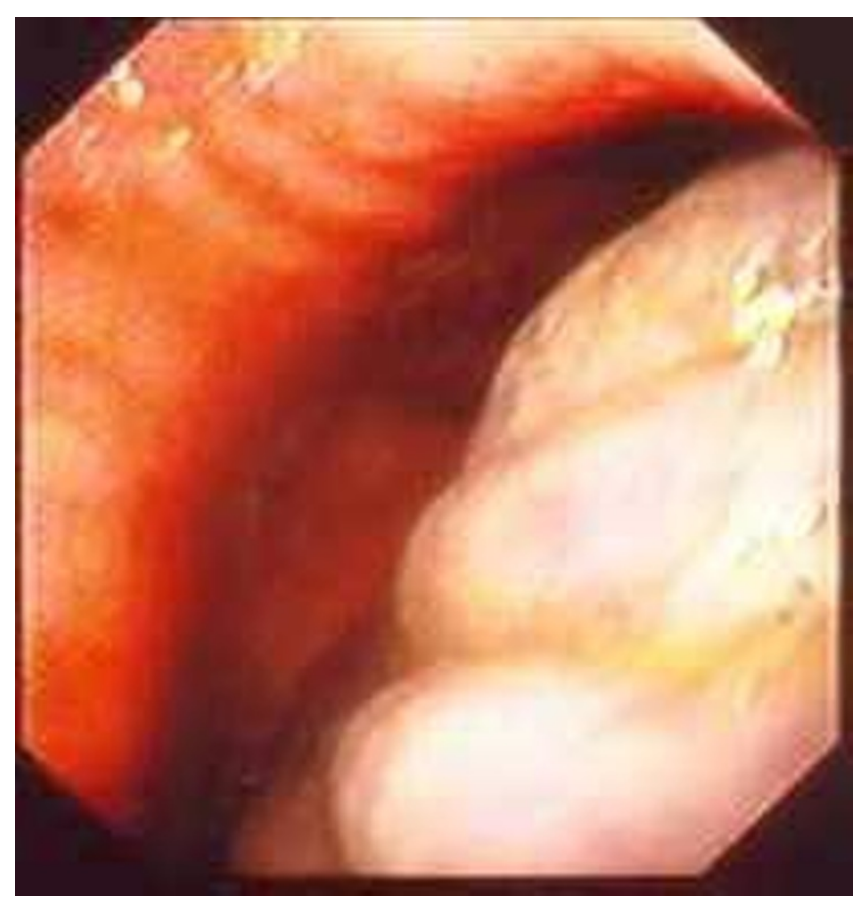

\section{Figure 4}

Endoscopic picture: Another view of a congested intestinal loop.

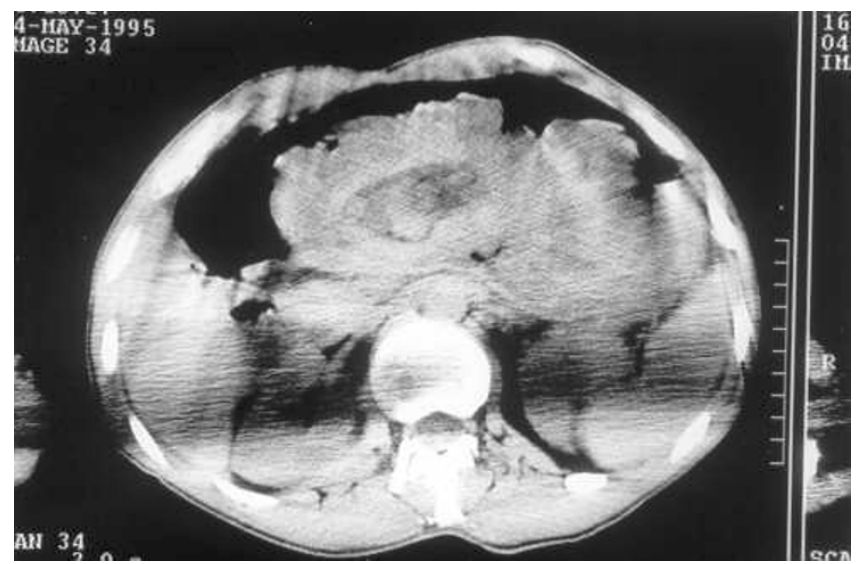

\section{Figure 5}

Emergency CT- Scan of the abdomen: Dilated stomach with intragastric non-homogeneous mass compatible with bowel loops.

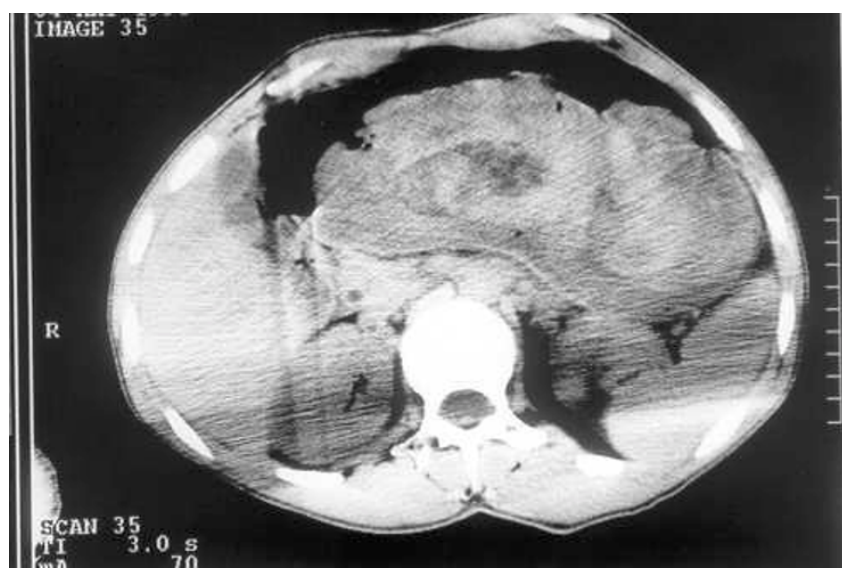

Figure 6

Emergency CT- Scan of the abdomen: Another section showing a dilated stomach with intragastric non-homogeneous mass compatible with bowel loops.

to gastric surgery, seems to be accepted as the cause of type II JGI by most authors[1,16].

Two forms of JGI have been clinically recognized: an acute and a chronic form. In the acute form, incarceration and strangulation of the intussuscepted loop generally occur whilst spontaneous reduction is usual in the chronic type. Thus, the acute form is characterized by acute severe colicky epigastric pain, vomiting and, subsequently, hematemesis. Epigastric tenderness and a palpable abdominal mass can be observed in about $50 \%$ and signs of high intestinal obstruction can also be found $[1,17,18]$. It should be pointed out that a sudden onset of epigastric pain, vomiting and subsequent hematemesis, and a palpable epigastric mass in a patient with a previous gastric surgery are thought as the classic 
triad of JGI[18]. The picture was absolutely typical in the case described here. In the chronic form, the symptoms may be roughly similar to the acute form but milder, transient and subside spontaneously[19].

Thus, the patient complains for recurrent episodes of upper abdominal discomfort that is exacerbated by the food and usually subsides 1-1.5 $\mathrm{h}$ after the meal. Nausea and vomiting can be also present but epigastric pain is the main patient's complaint[1]. Early diagnosis of the acute form is of paramount importance[3,4]. The clinical picture is almost diagnostic to the alert, sensitized physician. X-ray can be occasionally diagnostic[20]. Endoscopy [21,22] performed by someone familiar with this rare entity, is certainly diagnostic: this was the case in the patient presented here. In the chronic form, the diagnosis is difficult. In many of such patients, the correct diagnosis has never been established. The main reason for this is that upper GI series[20] or upper GI endoscopy must be performed during the symptomatic period for the diagnosis to be confirmed. However, it has been suggested[23] that in the asymptomatic period, the provocation of JGI during endoscopy by the use of a jet of water directed towards the anastomotic stoma may be diagnostic of the chronic form. It is clear that there is no medical treatment for acute JGI and the correct treatment is the surgical intervention as soon as possible. Surgical options include reduction, resection, revision of the anastomosis and the take-down of the anastomosis, depending on the conditions found during the operation[1]. The best way to prevent recurrence, if any, has not been identified yet $[1,23]$.

\section{References}

I. Waits JO, Beart RW Jr, Charboneau JW: Jejunogastric intussusception. Arch Surg 1980, I I 5: 1449-1452

2. Conklin EF, Markowitz AM: Intussusception-a complication of gastric surgery. Surgery 1965, 57:480-488

3. Shackman R: Jejunogastric intussusception. Br J Surg 1940, 27:475-480

4. Sibley WL: Chronic intermittent intussusception through the stoma of a previous gastro-enterostomy. Proc Staff Meet Mayo Clin 1934, 9:364-365

5. Bozzi E: Annotation. Bull Acad Med 1914, 122:3-4

6. Lundberg S: Retrograde Dunndarminvagination nach Gastroenterostomie. Acta Chir Scand 1922, 54:423-433

7. Shiffman M, Rappaport I: Intussusception following gastric resection. Am Surg 1966, 32:715-724

8. Salem MH, Coffman SE, Postlethwait RW: Retrograde intussusception at the gastrojejunal stoma. Ann Surg |959, I 50:864-87|

9. Lopez-Mut JV, Cubells M, Campos S, Miranda V, Rivera P: Jejunogastric intussusception: a rare complication of gastric surgery. Abdom Imaging 1998, 23:558-559

10. Wheatley MJ: Jejunogastric intussusception diagnosis and management. J Clin Gastroenterol 1989, I I:452-4

II. Gasparri MG, Pipinos II, Kralovich KA, Margolin DA: Retrograde jejunogastric intussusception. South Med J 2000, 93:499-500

12. Christeas N, Sfinias G: Retrograde jejunojejunal intussusception. Br J Clin Pract 1968, 22:439-44 |

13. Daniel P, Vieweg G: Retrograde Invagination des Jejunums nach Gastrektomie. Zbl Chir 1974, 99:57-59

14. Freeman J, Bernatz P, Brown P: Retrograde intussusception after total gastrectomy. Arch Surg 1966, 93:586-588
15. Reyelt WP Jr, Anderson AA: Retrograde jejunogastric intussusception. Surg Gynecol Obstet 1964, I 19:1 305-1311

16. Irons HS, Lipin RJ: Jejuno-gastric intussusception following gastroenterostomy and vagotomy. Ann Surg 1955, I 4I:54 I-546

17. White TT, Harrison RC: Reoperative Gastrointestinal Surgery. Little Brown and Company, 1973, 98-

18. Foster DG: Retrograde jejunogastric intussusception-a rare cause of hematemesis. AMA Arch Surg 1956, 73:1009-1017

19. Olsen AK, Bo O: Intussusception as a complication of partial gastrectomy-a case report. Acta Chir Scand 1978, 144:405-408

20. Jaaskelainen V: Retrograde intussusception after certain gastric operations. Ann Chir Gynaecol 1954, 5 (Suppl): I29-I35

21. Kallen R, Graffner H, Jonsson Per-Ebbe J: Jejunogastric intussusception through the enteroanastomosis after gastric resection. Case report. Acta Chir Scand 1986, 1 52:637-640

22. Truong SN, Tittel A, Schumpelick V: Die jejunogastrische Invagination-eine seltene Komplikation der Magenchirurgie. $Z$ Gastroenterol 1992, 30:798-800

23. Czeriak A, Bass A, Bat L, Shemesh E, Avigad I, Wolfstein I: Jejunogastric intussusception-a new diagnostic test. Arch Surg 1987, 122:1190-1192

\section{Pre-publication history}

The pre-publication history for this paper can be accessed here:

http://www.biomedcentral.com/content/backmatter/ 1471-230X-1-1-b1.pdf

Publish with BioMedcentral and every scientist can read your work free of charge

"BioMedcentral will be the most significant development for disseminating the results of biomedical research in our lifetime." Paul Nurse, Director-General, Imperial Cancer Research Fund

Publish with BMc and your research papers will be:

- available free of charge to the entire biomedical community

- peer reviewed and published immediately upon acceptance

- cited in PubMed and archived on PubMed Central

- yours - you keep the copyright

Submit your manuscript here:

http://www.biomedcentral.com/manuscript/

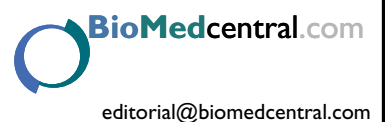

